\title{
Scalp Hypothermia (Penguin Cold Caps) in Preventing Alopecia in Cancer Patients
}

\author{
Dilek AYGíN, Aysel GÜL
}

Department of Surgical Nursing, Sakarya University, İstanbul-Turkey

\begin{abstract}
SUMMARY
Cancer morbidity and mortality are severe public health problems that are increasing day by day. In addition to their benefits of some methods, such as chemotherapy and radiotherapy, which are applied for cancer treatment, there are some side effects and complications, such as skin reactions, hair loss, fatigue, vomiting and loss of appetite. In this article, one of these complications and affecting more than half of the patients who receive cancer treatment alopecia will be mentioned. Alopecia may be temporary or permanent, but it has been stated by health professionals that this problem is often ignored. Alopecia affects body image in individuals, increases the level of stress, causes anxiety and depression and even individuals are exposed to stigma. The emergence of these problems in the patient also affects the quality of life negatively. To prevent alopecia, which can be seen especially due to chemotherapy, the process of cooling the scalp has started to be applied about 50 years ago and the materials used thanks to the changing materials science have been developed. In this study, the efficacy of scalp hypothermia (Penguin Cold Caps) in the prevention of alopecia, which is frequently seen due to chemotherapy, has been evaluated and it is aimed to investigate the relevant studies.
\end{abstract}

Keywords: Alopecia; cancer; hypothermia; patient; scalp.

Copyright $\odot$ 2020, Turkish Society for Radiation Oncology

\section{Introduction}

Cancer, which arises from the deterioration of health that is defined as a complete physical, social and mental wellness, is a globally important public health problem with its high mortality and increasing prevalence.[1,2] The risk of cancer is increased by negative lifestyles, such as smoking, drinking, bad dietary habits, physical inactivity, obesity, unhealthy sexual life and reproductive changes (e.g., miscarriages, late first birth) and exposure to environmental carcinogenic substances. As fertility decreased especially in developed countries and death rates decreased based on advanced diagnosis and treatment opportunities, the increase in the elderly population that lives with various chronic diseases (e.g., stroke, heart disease, diabetes, cancer) also contributes to the increased prevalence of cancer in patients.[3-11]

Cancer is held responsible for the death of one in every four people in the United States of America (USA), and it is even projected to become more prevalent than heart disease in the future. The World Health Organization (WHO) also stated that cancer has a significant place worldwide, new cases will be added in the next 20 years with an increase of $70 \%$, it is the second among the causes of death, and it was responsible for the death of 8.8 million people in the year 2015 . $[1,8,12]$ Each year in Europe, in parallel to the WHO and USA statistics, new cases of cancer increase (about 3.7 million), and cancer is found to lead to $20 \%$ of the deaths (1.9 million).[13] 
As in the entire world, cancer-related morbidity and mortality rates are high also in Turkey.[14,15] According to the 2016 results of the Turkish Statistical Institute, 174,000 people were newly diagnosed with cancer every year, and 80,577 of these people died. $[16,17]$

Today, the treatment of cancer involves surgery, chemotherapy, radiotherapy, immunotherapy, hormonotherapy, targeted therapies and gene therapy (biological therapies). In addition to the advantages of all treatment methods, temporary or permanent side effects, such as skin reactions, loss of hair, fatigue, vomiting and loss of appetite and complications, may occur based on the medicine that is used, as well as the characteristics of the patient.[18-21] This review article aimed to investigate whether or not using Scalp Hypothermia (Penguin Cold Caps), which is an alternative treatment for chemotherapy-related alopecia (loss of hair), especially in cancer patients, is effective in preventing hair loss and examined studies that have been carried out on this topic.

Chemotherapy regimens involve a complicated process that has a high incidence of morbidity and mortality. Several drugs show toxic effects even in therapeutic doses.[22] Chemotherapy causes several side effects that negatively affect the quality of life of individuals, such as immunosuppression, neutropenia, anemia, diarrhea, constipation, dyspnea, chest pain, pain, nausea, vomiting, fatigue, alopecia, myalgia, stomatitis, and hand, foot and mouth disease.[23-26]

\section{Alopecia}

Although alopecia is rarely reported in clinical studies as significant toxicity, it affects a large proportion of individuals who receive cancer treatment as 65\% and may be temporary or permanent. This problem, which affects the body image of individuals with cancer significantly, is usually neglected by healthcare professionals. $[27,28]$ If alopecia is resolved in the next 3-6 months after chemotherapy ended, it is known as "temporary alopecia," while it is known as "permanent alopecia" if the hair is not replaced for a time longer than six months.[28]

The main cause of alopecia is the damage to healthy cells, including hair-producing cells created by chemotherapy, which is aimed to kill the cancer cells that become abnormal by modifications, grow and spread rapidly.[29] The hair loss table, which varies from hair thinning to baldness, occurs in different periods from on to four weeks after the start of chemotherapy, and the hair loss progresses. In this process, individuals frequently complain about that groups of hair fall while washing or combing, as well as the feeling of sensitivity and itching. [29,30] Studies report hair loss only in the front part of the head in women and a loss in a broader area of the body in men.[31,32] Although there are advancements in treatment and care for side effects, such as emesis, pain, thrombosis, hematopoietic cytopenia, xerostomia and infection, improvements to the desired extent have not been achieved in the prevention and treatment of alopecia.[33] However, it is possible to reduce hair loss by adjusting the dose programs and combinations of cytotoxic agents, applying low doses through an extended time period and changing the ways of administering these agents. [33,34]

Considering the effects of hair on body image and women especially as a symbol of health, attractiveness and femininity, hair loss causes anxiety and stress in the individual, individuals are exposed to self-alienation in addition to stigma, and quality of life is affected negatively.[35-39] In 65-85\% of the patients who experience chemotherapy-related alopecia, [40] it was reported that sexual lives are affected negatively in addition to low self-image and depression and deterioration in physical, cognitive, emotional and social functions.[40,41] Two different studies with similar results reported that more than half of patients considered alopecia to be the most traumatic aspect of the treatment process, $[39,42]$ and some patients event thought about refusing treatment due to this side effect.[42] $\mathrm{Pa}$ tients who were informed about this issue beforehand made psychological preparations by shortening their hair before alopecia kicked in and stated that they were not satisfied new tissue and color of their hair, which grew after completing the treatment process. [36] Thus, it was understood that the negative perceptions that the individual is exposed to, unpreparedness and limited social support increased alopecia-related issues even further.[43]

In the literature, hair loss is discussed concerning death, old age, sexuality, attractiveness, loss of uniqueness and an appearance of disease.[44-46] In recent years, healthcare professionals have tried to reduce the negative effects of alopecia on the individual by taking mechanical, physical and biological precautions.

\section{Scalp Hypothermia}

To prevent chemotherapy-related alopecia, the procedure of cooling the scalp by reducing the temperature of the skin has been used since the 1970s. [47] In that period, broken pieces of ice that were placed into plastic bags emerged as a promising method. With the development of the methodology of this technique since then, the main principle of hypothermia 
treatment has stayed the same due to its successful outcomes.[32-48] With the effects of vasoconstriction, scalp hypothermia is based on the principle of slowing down the intrafollicular metabolism by reducing the perfusion of the scalp, thus hair follicles. [44,49-51] Advantages and disadvantages of cooling the scalp are shown in Table 1. Today, it was seen that cooling down the scalp is the most effective protective intervention during chemotherapy with positive outcome rates of $50 \%$ to $80 \%$.[41]

If studies that investigated whether or not scalp hypothermia is effective are examined, van den Hurk et al. (2012), who discussed the positive outcomes of such implementations found that there was no need for wigs or head covers in $81 \%$ of 53 patients who received scalp hypothermia therapy during chemotherapy treatment. [52] Another similar study applied scalp hypothermia on 1411 patients in the last session of chemotherapy, and it was seen that there was no need for wigs of head covers in 50\% of the patients. [53] In addition to these positive outcomes, undesired side effects, although at low rates, may be encountered in the form of headache, sense of coldness, nausea, needle phobia, claustrophobia and increased distress.[47,54-57] Moreover, this treatment may have contraindications for patients with the common cold, cold agglutinin disease, cryofibrinogenemia and post-traumatic cold dystrophia, and rarely those with metastasis in the scalp. As tumor cells that take root from the scalp will not be affected by chemotherapy sufficiently during hypothermia, there might be a chance of relapse of the tumor after the treatment. [58] For example, the study by Rugo et al. (2017) in the USA reported that they needed to stop the implementation in four patients (3.8\%) due to headache and three patients $(2.8 \%)$ due to common cold among their 106 patients in the scalp hypothermia group.[59]
A non-pharmacological method that is currently used in scalp hypothermia and found to be successful in preventing alopecia is the method of Penguin Cold Caps. The project of the Penguin Cold Cap Registry was started in 2010 by the University of California San Francisco (UCSF).[60] In the study by Rice et al. (2018), where the effectiveness and tolerability of scalp hypothermia were assessed using Penguin Cold Caps in breast cancer patients, hair loss was assessed by both the patients and implementers every 3-4 weeks during chemotherapy and at least one month after completing chemotherapy. The patients assessed their own hair loss (five-point Dean's scale), satisfaction levels (VAS; Visual Analog Scale, 0-100 points) and their tolerances for the severity of headache, scalp pains and other side effects using VAS-like scales.[60] In general, it was found that Penguin Cold Caps application successfully prevented chemotherapy-related alopecia in $61 \%$ of the patients, and this effect was specific to the treatment regimen that was applied (Docetaxel/carboplatin/trastuzumab $100 \%$, Docetaxel/cyclophosphamide $84 \%$, Docetaxel/ cyclophosphamide 50\%, Paclitaxel/Doxorubicin/ cyclophosphamide 43\%, Doxorubicin/cyclophosphamide/Paclitaxel 20\%). The most frequently observed side effect of the application was headache by $78.5 \%$. It was seen that the satisfaction levels of the patients who completed the scalp cooling treatment varied in the range of $74 \%-100 \%$, scalp hypothermia by Penguin caps was effective in reducing alopecia, especially for non-anthracycline short regimens, it was tolerated well and assessed to be a positive practice by most patients.[60]

In another randomized controlled study where the effectiveness of the Penguin Cold Caps system and the views of female patients on it were investigated, gel

Table 1 Advantages and disadvantages of the cooling the scalp. $[47,53,54,57,57,64,65]$

\section{Scalp cooling}

\section{Advantages}

Enables to protect your hair more.

Reduces the need for wig or headscarf.

Even if you have hair loss during the treatment, scalp cooling enables a faster regrowth.

Provides some opportunities for doing something against the boldness.

Scalp cooling can increase satisfaction in the individuals concerning its positive outcomes.

\section{Disadvantages}

Extends your hospitalization period.

Does not guarantee the protection of hair; outcomes are uncertain. Hair quality may reduce.

The cooling applied may cause headaches or dizziness, especially for the first 15 minutes.

If the scalp cooling fails, it may cause extra disappointment.

Unintended side effects can be faced, such as the sense of coldness, common cold, nausea, trypanophobia, claustrophobia and increased distress. 
head covers were changed three times in a total of two hours to keep the temperature of the scalp below $-18^{\circ} \mathrm{C}$ in the treatment group, and the patients were assessed by surveys and photographs through their chemotherapy cycles ( 5 Fluorouracil $600 \mathrm{mg} / \mathrm{m}^{2}$, Epirubicin 50 $\mathrm{mg} / \mathrm{m}^{2}$, Cyclophosphamide $600 \mathrm{mg} / \mathrm{m}^{2}$ ). While there was no significant hair loss in $30 \%$ of the 10 patients in the treatment group, there was mild hair loss in $40 \%$ and severe hair loss in $20 \%$. While all the control group patients (5 patients) needed wigs, there was no need for it in $70 \%$ of the treatment group patients.[54]

In the study by Katsimbri et al. (2000), 30 minutes before starting the chemotherapy treatment (at least one of taxanes, anthracyclines or etoposide drugs), Crylon Gel caps made out of polyurethane material were used on patients to keep the temperature of the scalp at $-15^{\circ} \mathrm{C}$, the caps were changed at every $35 \mathrm{~min}$ utes during two hours of chemotherapy, and cap treatment continued for two hours after the chemotherapy treatment ended. Hair loss was assessed on five levels; not needing wigs was considered to be a success in patients who were divided into four groups based on their drug combinations, and a success rate of $81 \%$ was achieved in general.[61]

A similar study was carried out by Kargar et al. (2011), and the results of 31 patients who accepted using Penguin Cold Caps and 32 patients who refused it were compared. In their study, the entire process lasted 120 minutes from 15 minutes before starting chemotherapy in a way to keep the scalp temperature under $-20^{\circ} \mathrm{C}$ and keep each cap in contact for 45 minutes. There were significant differences in the $2^{\text {nd }}-6^{\text {th }}$ cycles between the two groups of patients who were assessed based on the Alopecia Guidelines by WHO. There was no significant hair loss or mild hair loss in $77.4 \%$ of the patients in the hypothermia group. Severe or complete alopecia was observed in $22.6 \%$ of the experiment group and $61.3 \%$ of the control group. Accordingly, it was concluded that the Penguin Cold Caps method was an effective method in preventing chemotherapyrelated alopecia.[62]

Cigler et al. (2015) applied scalp hypothermia down to $-32^{\circ} \mathrm{C}$ by Penguin Cold Caps (polyurethane filled with cryogenic insulation material) on women with early-stage breast cancer who received adjuvant chemotherapy treatment with docetaxel and cyclophosphamide. The process of cooling the scalp was started 50 minutes before the chemotherapy, and the caps were changed every 30 minutes during chemotherapy infusion and for four hours after completion. The women were asked to avoid hair products that contain alcohol or peroxide, wash their hair at most two times every week with shampoo and lukewarm water using gentle motions, avoid hair dyes and not use hairdryers, hair straighteners or curling irons from two weeks before chemotherapy and up to four months after the completion of the treatment. Alopecia was assessed by Dean's Scale before each chemotherapy session and after chemotherapy in varying intervals between three weeks and three months. It was reported that no patients quit the treatment due to reasons like side effects, they tolerated the scalp cooling process well, and successful results (65\% excellent, $25 \%$ good, $10 \%$ medium/bad hair loss) were obtained.[63] The results of the studies related to scalp cooling according to the type of chemotherapy and their results are summarized in Table 2.

\section{Conclusion}

Consequently, it is highly important for healthcare professionals to show a proactive and supportive attitude towards prevention, treatment and care for chemotherapy-related alopecia and develop the coping strategies of the patients. Non-pharmacologic methods that develop through time and alternative medical practices are a significant part of nursing care, and these will provide important contributions in the improvement of the outcomes of treatment and care. It is believed that, for preventing alopecia, studies with large samples and well-organized methodologies should be conducted. We are of the opinion that the evidentiality of this practice may be increased by conducting future studies on scalp cooling practices, such as those that involve Penguin Cold Caps with different types of cancer and new drug combinations, with caps containing different materials and considering different time intervals/temperatures.

Peer-review: Externally peer-reviewed.

Conflict of Interest: None declared.

Financial Support: No financial support or assistance from any person or organization was received for this study.

\section{References}

1. World Health Organization database: Health Systems Strengthening Glossary retrieved. Available at: http:// www.who.int/healthsystems/hss_glossary/en/index5. html Accessed Feb 3, 2020.

2. Gonzalez VJ, McMillan S, Pedro E, Tirado-Gomez M, Saligan LN. The Health related Quality of Life of Puerto Ricans during Cancer Treatments; A Pilot Study. P R Health Sci J 2018;37(1):46-51. 


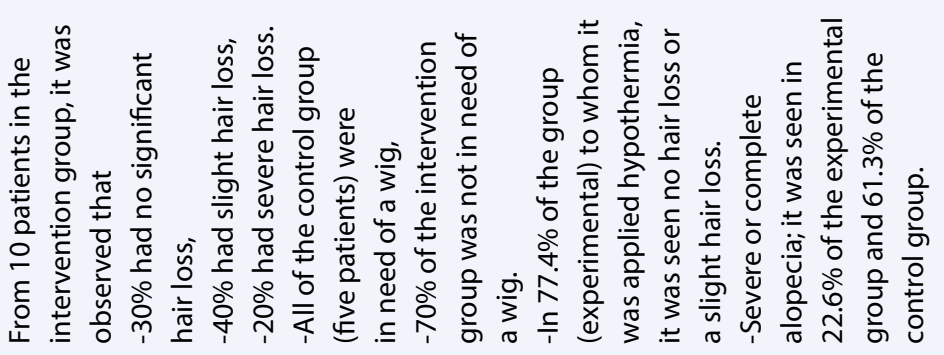

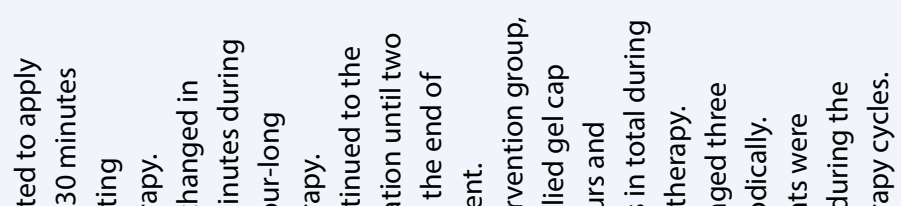
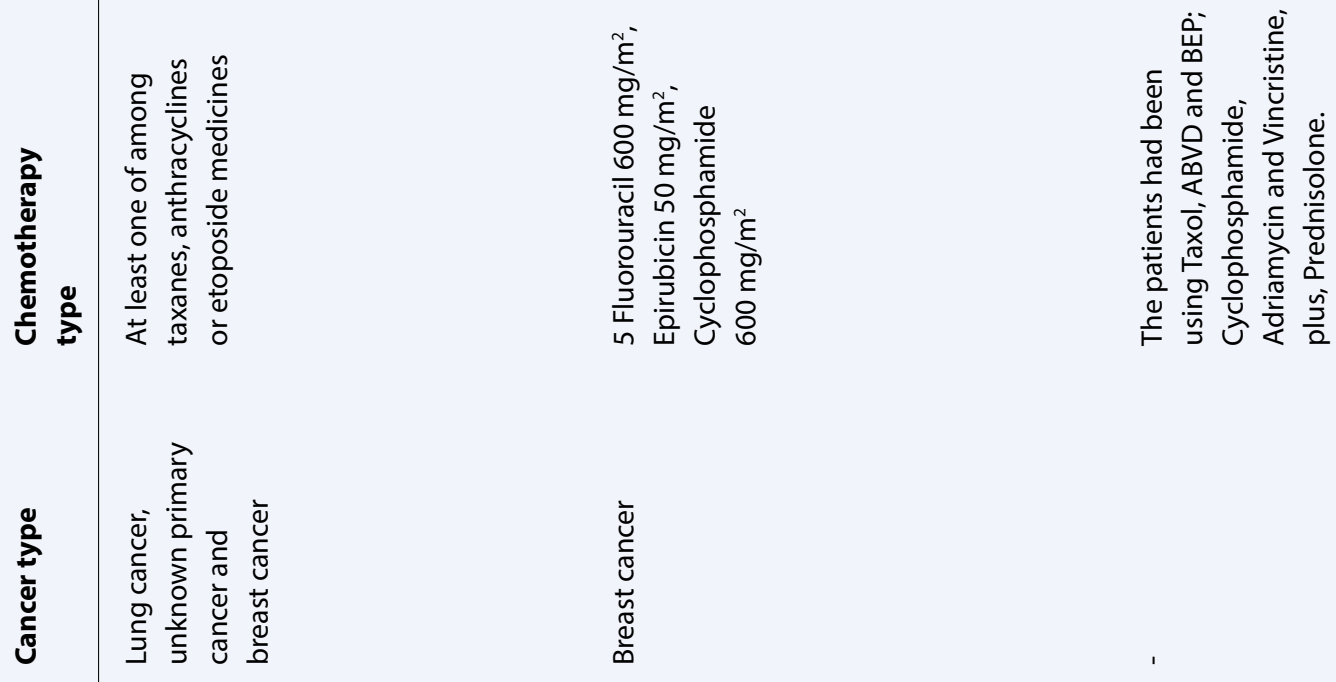

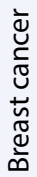
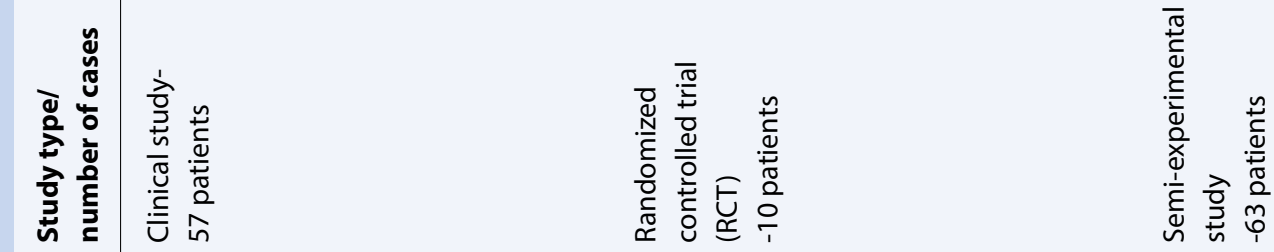

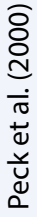

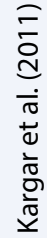




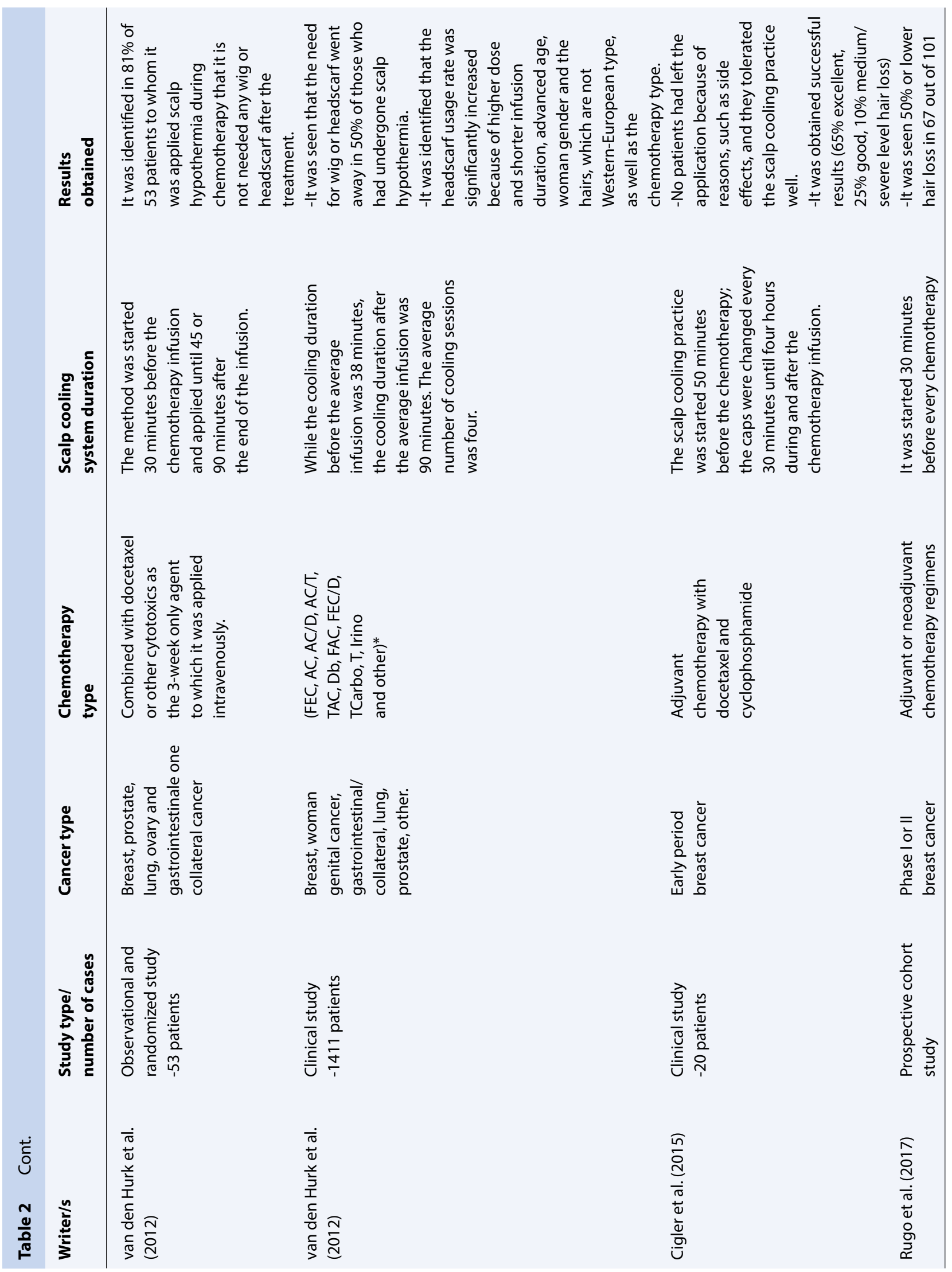




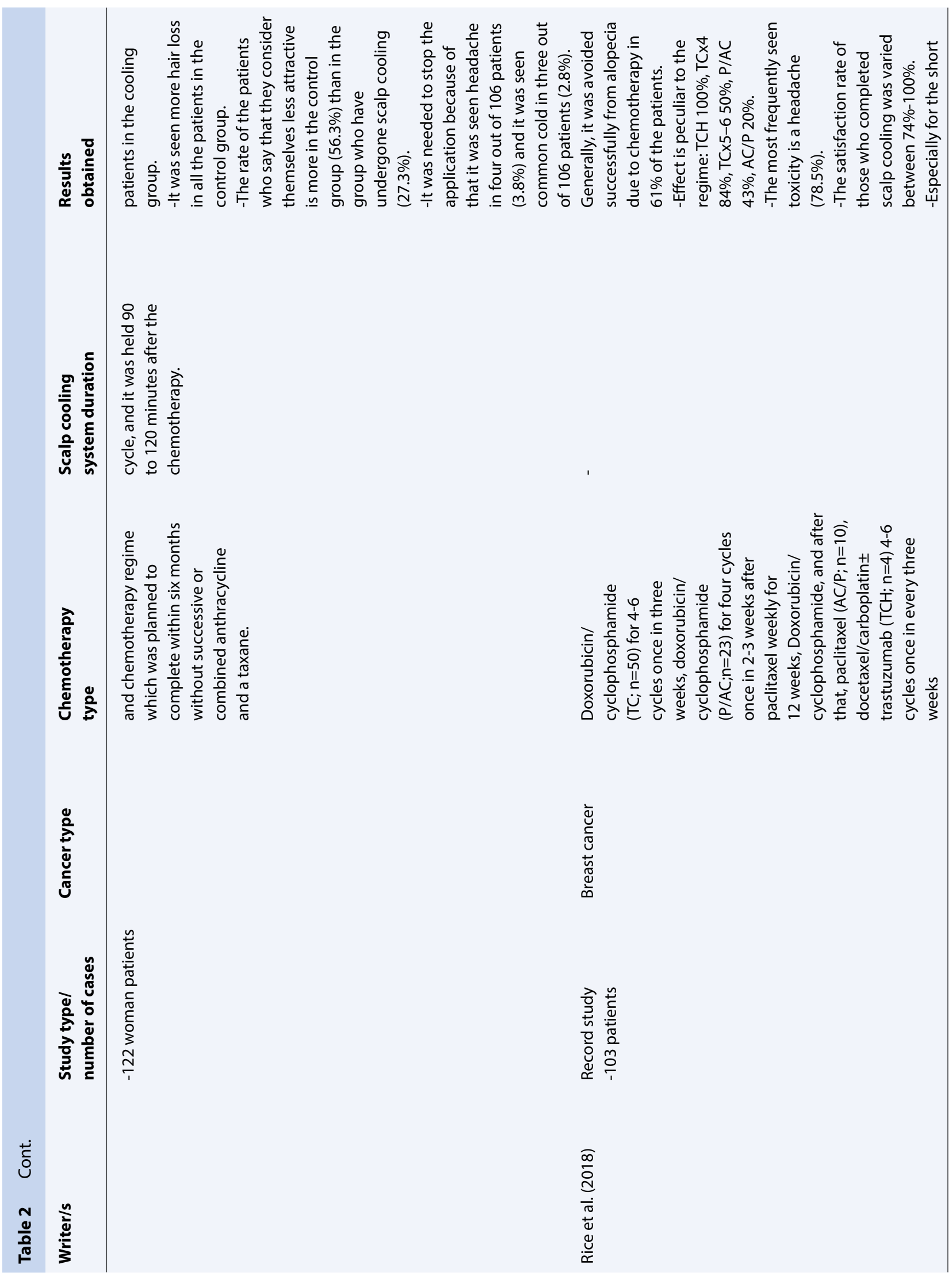




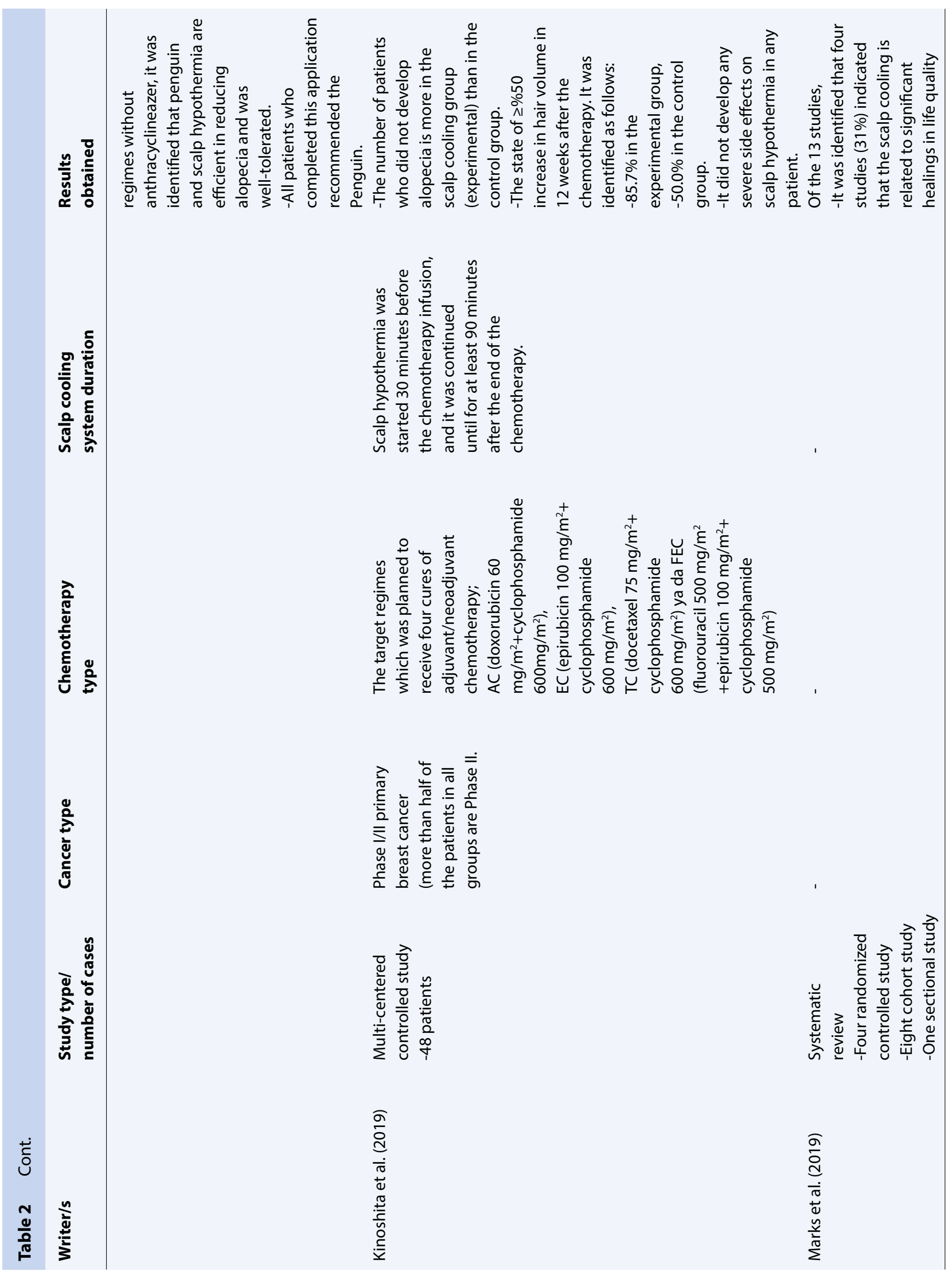




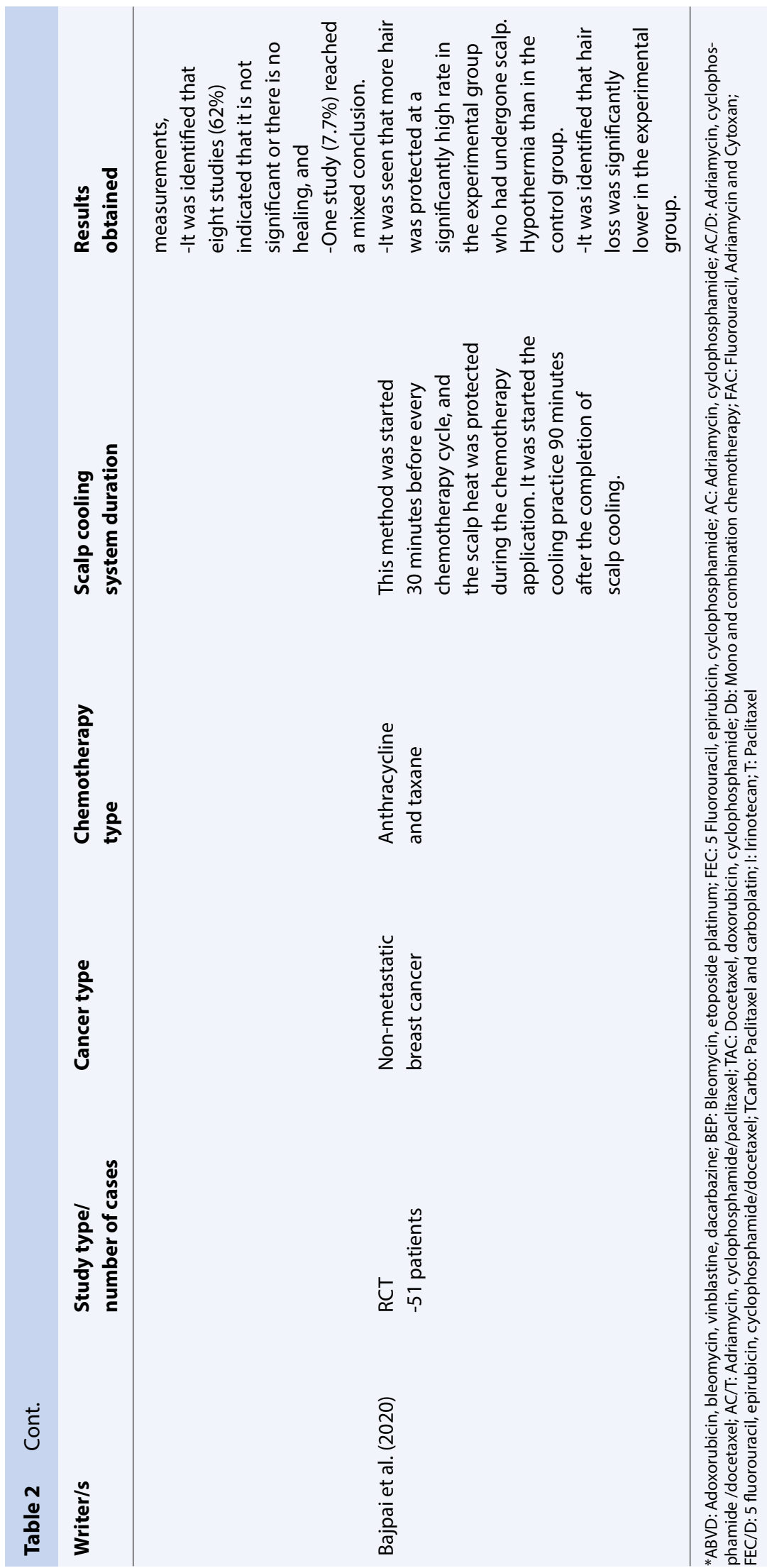


3. Torre LA, Bray F, Siegel RL, Ferlay J, Lortet-Tieulent J, Jemal A. Global cancer statistics, 2012. CA Cancer J Clin 2015;65(2):87-108.

4. Menon A, Handattu S, Shetty J, Shanmukha Girisha B. Study of Cutaneous Adverse Effects of Cancer Chemotherapy. Clinical Dermatology Review 2018;2(1):19-24.

5. Beard JR, Officer A, de Carvalho IA, Sadana R, Pot AM, Michel JP, et al. The World report on ageing and health: a policy framework for healthy ageing. Lancet 2016;387(10033):2145-54.

6. Clarfield AM. Healthy Life Expectancy Is Expanding. J Am Geriatr Soc 2018;66(1):200-1.

7. Yaghoobzadeh A, Gorgulu O, Yee BL, Wibisono AH, Pahlevan Sharif S, Sharif Nia H, et al. A Model of Aging Perception in Iranian Elders With Effects of Hope, Life Satisfaction, and Socioeconomic Status: A Path Analysis. J Am Psychiatr Nurses Assoc 2018;24(6):522-30.

8. World Health Organization database: Cancer fact sheet retrieved. Available at: http://www.who.int/mediacentre/factsheets/fs297/en/. Accessed Feb 3, 2020.

9. DuGoff EH, Canudas-Romo V, Buttorff C, Leff B, Anderson GF. Multiple Chronic Conditions and Life Expectancy: A Life Table Analysis. Med Care 2014;52(8):688-94.

10. Demmer RT, Barondess JA. On the Communicability of Chronic Diseases. Ann Intern Med 2018;168(1):6970.

11. World Health Organization database: The top 10 causes of death fact sheet retrieved. Available at: http:// www.who.int/mediacentre/factsheets/fs310/en/. Accessed Feb 3, 2020.

12. Kemp BR, Ferraro KF, Morton PM, Mustillo SA. Early Origins of Adult Cancer Risk Among Men and Women: Influence of Childhood Misfortune? J Aging Health 2018;30(1):140-63.

13. World Health Organization Regional Office for Europe database: from data and statistics fact sheet retrieved. www.euro.who.int/en/health.../cancer/data-and-statistics [visited March 25, 2018].

14. National Cancer Institute database: What Is Cancer?. https://www.cancer.gov/about-cancer/.../what-iscancer [visited March 26, 2018].

15. Cancer Research UK database: What is cancer?. Available at: www.cancerresearchuk.org/about-cancer/ what-is-cancer. Accessed Feb 3, 2020.

16.12.Türkiye Kanser İstatistikleri. http://kanser.gov. tr/Dosya/ca_istatistik/ANA_rapor_2013v01_2.pdf [Erişim Tarihi: 12.02.2018].

17. 13.Türkiye İstatistik Kurumu. Ölüm Nedeni İstatistikleri. Available at: http://www.tuik.gov.tr/PreHaberBultenleri.do?id=24572. Accessed Feb 4, 2020.
18. Fokas E, Rödel C. Targeted agents in GI radiotherapy: Clinical efficacy and side effects. Best Pract Res Clin Gastroenterol 2016;30(4):537-49.

19. Baykara O. Current Modalities In Treatment Of Cancer. Balıkesır Health Sciences Journal 2016;5(3):154-65.

20. Halk Sağlığı Genel Müdürlüğü. Kanser Tedavi Nelerdir? Available at: http://www.kanser.saglik.gov.tr/. Accessed Feb 4, 2020.

21. Ünal O, Kars B. Postmenapozal hormon tedavisi (HT) ve kanser riski. TJOD-Uzmanlık Sonrası Eitim ve Güncel Gelimeler 2004;1:51-7.

22. Na Z, Qiaoyuan Y, Binghan W, Qin Z, Yue C, Xin P, et al. A developed model of cancer patients participation in intravenous chemotherapy safety. Oncotarget 2017;8(50):87598-606.

23. Beusterien K, Grinspan J, Kuchuk I, Mazzarello S, Dent S, Gertler S, et al. Use of conjoint analysis to assess breast cancer patient preferences for chemotherapy side effects. Oncologist 2014;19(2):127-34.

24. Demaria M, O'Leary MN, Chang J, Shao L, Liu S, Alimirah F, et al. Cellular Senescence Promotes Adverse Effects of Chemotherapy and Cancer Relapse. Cancer Discov 2017;7(2):165-76.

25. Pearce A, Haas M, Viney R, Pearson SA, Haywood P, Brown C, et al. Incidence and severity of self-reported chemotherapy side effects in routine care: A prospective cohort study. PLoS One 2017;12(10):e0184360.

26. Gurung S, Pandey RA. Perception of Side Effects of Chemotherapy among Cancer Patients in B.P. Koirala Memorial Cancer Hospital Bharatpur. Journal of College of Medical Sciences-Nepal 2015;11(4):14-9.

27. Dua P, Heiland MF, Kracen AC, Deshields TL. Cancerrelated hair loss: a selective review of the alopecia research literature. Psychooncology 2017;26(4):43843.

28. Kim GM, Kim S, Park HS, Kim JY, Nam S, Park S, et al. Chemotherapy-induced irreversible alopecia in early breast cancer patients. Breast Cancer Res Treat 2017;163(3):527-33.

29. Muth CC. Chemotherapy and Hair Loss. JAMA 2017;317(6):656.

30. West HJ. Chemotherapy-Induced Hair Loss (Alopecia). JAMA Oncol 2017;3(8):1147.

31. Hilton S, Hunt K, Emslie C, Salinas M, Ziebland S. Have men been overlooked? A comparison of young men and women's experiences of chemotherapy-induced alopecia. Psychooncology 2008;17(6):577-83.

32. Villasante A C, Herskovitz I, Mauro LM, Jimenez J J. Chemotherapy-Induced Alopecia. J Clin Investigat Dermatol 2014;2(2):1-8.

33. Hesketh PJ, Batchelor D, Golant M, Lyman GH, Rhodes N, Yardley D. Chemotherapy-induced alope- 
cia: psychosocial impact and therapeutic approaches. Support Care Cancer 2004;12(8):543-9.

34. Dąbrowski T. Hair loss as a consequence of cancer chemotherapy - physical methods of prevention. A review of the literature. Contemporary Oncology 2011;2(2):95-101.

35. Trusson D, Pilnick A. The Role of Hair Loss in Cancer Identity: Perceptions of Chemotherapy-Induced Alopecia Among Women Treated for Early-Stage Breast Cancer or Ductal Carcinoma in Situ. Cancer Nurs 2017;40(2):E9-E16.

36. Jayde V, Boughton M, Blomfield P. The experience of chemotherapy-induced alopecia for Australian women with ovarian cancer. Eur J Cancer Care (Engl) 2013;22(4):503-12.

37. Erol O, Can G, Aydıner A. Effects of alopecia on body image and quality of life of Turkish cancer women with or without headscarf. Support Care Cancer 2012;20(10):2349-56.

38. Baati I, Mnif L, Masmoudi J, Allouche C, Damak R, Halwani N, et al. Psychological impact of chemotherapy induced alopecia. European Psychiatry 2010;25(1):869.

39. Choi EK, Kim IR, Chang O, Kang D, Nam SJ, Lee JE, et al. Impact of chemotherapy-induced alopecia distress on body image, psychosocial well-being, and depression in breast cancer patients. Psychooncology 2014;23(10):1103-10.

40. Katikaneni R, Ponnapakkam T, Matsushita O, Sakon J, Gensure R. Treatment and prevention of chemotherapy-induced alopecia with PTH-CBD, a collagen-targeted parathyroid hormone analog, in a non-depilated mouse model. Anticancer Drugs 2014;25(1):30-8.

41. Rubio-Gonzalez B, Juhász M, Fortman J, Mesinkovska NA. Pathogenesis and treatment options for chemotherapy-induced alopecia: a systematic review. Int J Dermatol 2018;57(12):1417-24.

42. Balagula Y, Rosen ST, Lacouture ME. The emergence of supportive oncodermatology: the study of dermatologic adverse events to cancer therapies. J Am Acad Dermatol. 2011;65(3):624-35.

43. Kim IR, Cho J, Choi EK, Kwon IG, Sung YH, Lee JE, et al. Perception, attitudes, preparedness and experience of chemotherapy-induced alopecia among breast cancer patients: a qualitative study. Asian Pac J Cancer Prev 2012;13(4):1383-8.

44. Batchelor D. Hair and cancer chemotherapy: consequences and nursing care--a literature study. Eur J Cancer Care (Engl) 2001;10(3):147-63.

45 . Hunt N, McHale S. The psychological impact of alopecia. BMJ 2005;331(7522):951-3.
46. Carelle N, Piotto E, Bellanger A, Germanaud J, Thuillier A, Khayat D. Changing patient perceptions of the side effects of cancer chemotherapy. Cancer 2002;95(1):155-63.

47. Komen MM, Smorenburg CH, van den Hurk CJ, Nortier JW. Factors influencing the effectiveness of scalp cooling in the prevention of chemotherapy-induced alopecia. Oncologist 2013;18(7):885-91.

48. Belum VR, de Barros Silva G, Laloni MT, Ciccolini K, Goldfarb SB, Norton L, et al. Cold thermal injury from cold caps used for the prevention of chemotherapy-induced alopecia. Breast Cancer Res Treat 2016;157(2):395-400.

49. Ridderheim M, Bjurberg M, Gustavsson A. Scalp hypothermia to prevent chemotherapy-induced alopecia is effective and safe: a pilot study of a new digitized scalp-cooling system used in 74 patients. Support Care Cancer 2003;11(6):371-7.

50. Nangia J, Wang T, Osborne C, Niravath P, Otte K, Papish S, et al. Effect of a Scalp Cooling Device on Alopecia in Women Undergoing Chemotherapy for Breast Cancer: The SCALP Randomized Clinical Trial. JAMA 2017;317(6):596-605.

51. Shin H, Jo SJ, Kim DH, Kwon O, Myung SK. Efficacy of interventions for prevention of chemotherapy-induced alopecia: a systematic review and meta-analysis. Int J Cancer 2015;136(5):E442-54.

52. van den Hurk CJ, Breed WP, Nortier JW. Short postinfusion scalp cooling time in the prevention of docetaxel-induced alopecia. Support Care Cancer 2012;20(12):3255-60.

53. van den Hurk CJ, Peerbooms M, van de Poll-Franse LV, Nortier JW, Coebergh JW, Breed WP. Scalp cooling for hair preservation and associated characteristics in 1411 chemotherapy patients - results of the Dutch Scalp Cooling Registry. Acta Oncol 2012;51(4):497504.

54. Peck HJ, Mitchell H, Stewart AL. Evaluating the efficacy of scalp cooling using the Penguin cold cap system to reduce alopecia in patients undergoing chemotherapy for breast cancer. Eur J Oncol Nurs 2000;4(4):246-8.

55. Ekwall EM, Nygren LM, Gustafsson AO, Sorbe BG. Determination of the most effective cooling temperature for the prevention of chemotherapy-induced alopecia. Mol Clin Oncol 2013;1(6):1065-71.

56. van den Hurk CJ, Mols F, Vingerhoets AJ, Breed WP. Impact of alopecia and scalp cooling on the wellbeing of breast cancer patients. Psychooncology 2010;19(7):701-9.

57. Mols F, van den Hurk CJ, Vingerhoets AJ, Breed WP. Scalp cooling to prevent chemotherapy-induced hair 
loss: practical and clinical considerations. Support Care Cancer 2009;17(2):181-9.

58. Grevelman EG, Breed WP. Prevention of chemotherapy-induced hair loss by scalp cooling. Ann Oncol 2005;16(3):352-8.

59. Rugo HS, Klein P, Melin SA, Hurvitz SA, Melisko ME, Moore A, et al. Association Between Use of a Scalp Cooling Device and Alopecia After Chemotherapy for Breast Cancer. JAMA 2017;317(6):606-14.

60. Rice BA, Ver Hoeve ES, DeLuca AN, Esserman LJ, Rugo HS, Melisko ME. Registry study to assess hair loss prevention with the Penguin Cold Cap in breast cancer patients receiving chemotherapy. Breast Cancer Res Treat 2018;167(1):117-22.

61. Katsimbri P, Bamias A, Pavlidis N. Prevention of chemotherapy-induced alopecia using an effective scalp cooling system. Eur J Cancer 2000;36(6):76671.

62. Kargar M, Sarvestani RS, Khojasteh HN, Heidari MT. Efficacy of penguin cap as scalp cooling system for prevention of alopecia in patients undergoing chemotherapy. J Adv Nurs 2011;67(11):2473-7.

63. Cigler T, Isseroff D, Fiederlein B, Schneider S, Chuang E, Vahdat L, et al. Efficacy of Scalp Cooling in Preventing Chemotherapy-Induced Alopecia in Breast Cancer Patients Receiving Adjuvant Docetaxel and $\mathrm{Cy}-$ clophosphamide Chemotherapy. Clin Breast Cancer 2015;15(5):332-4.

64. van den Hurk C, Keizer-Heldens P, Raats I, Hoeijmakers K, Mols F. Improving Information Provision on Chemotherapy-Induced Alopecia and Scalp Cooling: A Comprehensive Approach Including A Website and Web-Based Decision Tool. Asia Pac J Oncol Nurs 2019;6(4):336-42.

65. Rugo HS, Melin SA, Voigt J. Scalp cooling with adjuvant/neoadjuvant chemotherapy for breast cancer and the risk of scalp metastases: systematic review and meta-analysis. Breast Cancer Res Treat 2017;163(2):199-205.

66. Kinoshita T, Nakayama T, Fukuma E, Inokuchi M, Ishiguro H, Ogo E, et al. Efficacy of Scalp Cooling in Preventing and Recovering From Chemotherapy-Induced Alopecia in Breast Cancer Patients: The HOPE Study. Front Oncol 2019;9:733.

67. Marks DH, Okhovat JP, Hagigeorges D, Manatis-Lornell AJ, Isakoff SJ, Lacouture ME, et al. The effect of scalp cooling on CIA-related quality of life in breast cancer patients: a systematic review. Breast Cancer Res Treat 2019;175(2):267-76.

68. Bajpai J, Kagwade S, Chandrasekharan A, Dandekar S, Kanan S, Kembhavi Y, et al. Randomised controlled trial of scalp cooling for the prevention of chemotherapy induced alopecia. Breast 2020;49:187-93. 